\title{
Cost-effective Treatment Technology on Textile Industrial Wastewater in Bangladesh
}

\author{
M. Shohidullh Miah \\ Director and Coordinator \\ College of Agricultural Sciences, IUBAT-International University of Business Agricultureand Technology \\ 4 Embankment Drive Road (off Dhaka- Ashulia Road), \\ Sector 10, Uttara Model Town, Dhaka-1230, Bangladesh
}

\begin{abstract}
\section{Introduction}

Most of urban areas in Bangladesh are facing severe long-term aquatic environmental pollution primarily caused by direct discharge of liquid textile wastewater in the waterways. The textile wastewater is a serious environmental challenge faced by Bangladesh textile sub sector.
\end{abstract}

To minimize the cost effective treatment process a treatment process has been setup at Dalas Fashion Ltd and Liz Fashion Ltd, Gazipur, Dhaka. The treatment process consisted of a combined process (anaerobic and bio-filtration process) to remove the pollution through biological process. The anaerobic process followed by Up-flow Anaerobic Sludge Blanket (UASB) process and Bio-filtration was maintained by polyurethane materials followed by down-flow process. The treatment processes are successfully operating without any chemical treatment process being thus more economic than the traditional chemical alternative. The raw textile wastewater is highly polluted with the characteristics of high alkaline in nature, $p H=9-10$, suspended biomass TSS $=1229-1500 \mathrm{mg} / \mathrm{l}$, Chemical oxygen demand, CODt $=$ $1448-2000 \mathrm{mg} / \mathrm{l}$, and biological oxygen demand, BODt=550-800 mg/l. Significant reductions were achieved to remove TSS (98\%) through bio-filtration process. In addition in the final effluent the removal efficiency were found CODt (98\%), $B O D(94 \%)$ and color were removed significantly. Total cost taka 89.84 million per year for the chemical ETP process. On the contrary, for UASB ETP requires a total cost taka 17.84 million per year.

Keywords: Solid separation, bio-filter, UASB, Effluent, without chemical

Most of the developing countries did not maintain any treatment process for wastewater and some of the countries just follow the traditional methods such as stabilizing ponds for wastewater treatment without applying the treatment process (de Sousa et al., 1996). Stabilizing pond takes very long time, extensive land area is required, spread a serious noxious smell and affects the air pollution, creates the potential breeding field for mosquitoes which affect seriously the public health and spreads diseases. The Up-flow Anaerobic Sludge Blanket (UASB) treatment system has been developed first time in Netherlands in 1970s (Lettinga and Vinken, 1980). Thereafter, the intensive use of UASB system has been developed for wastewater treatment over the past decades in developing countries in the tropical and subtropical regions such as Brazil, Colombia, China, India, and Mexico (Ciftci and Oztiirk 1995, Miah et al., 2004).

The textile wastewater contains organic compounds and synthetic chemicals. Certain chemicals which are used in the textile industry cause environmental or health problems. Due to presence of chemicals, it causes instance allergic skin reaction or even cause cancer. The major raw material for textile processing is grey fabric and most of materials consist of cotton and blended fabric. Textile processing employs a variety of chemicals depending on the nature of raw material and products such as; enzymes, detergents, dyes, acids, soda and salt. The textile wastewater is a highly polluted in terms of organic matter and suspended matter such as fibers, grease and chemicals. The textile wastewater is usually hot and alkaline with strong offensive smell and color due to use of dyes and chemicals. The high rate biological ETP is more popular, because;

i) It has high rate of anaerobic treatment capacity.

ii) Treatment efficiency well under mesophilic temperature condition,

iii) High organic strength wastewater can be treated,

iv) Relatively simple and low operation cost

v) High organic removal efficiency,

vi) Bio-energy benefit could be obtained through the biogas production and

vi) Excess sludge production is very low compared to conventional treatment process.

The objective of this work is to evaluate the cost effective ETP system development in Bangladesh.

\section{Materials \& Methods}

To minimize the pollution, a cost-effective biological treatment process has been set up at Mascom Composite textile dyeing factory, Gazipur, Dhaka and Dalas Fashion Ltd., Shofipur, Dhaka. The treatment process consist with a combined process (anaerobic and aerobic i.e., bio-filtration process) to remove the pollution materials through biological process. The design and treatment process are as follows:

*Corresponding Author: M. Shohidullh Miah

E-mail: drshohidullah@iubat.edu 


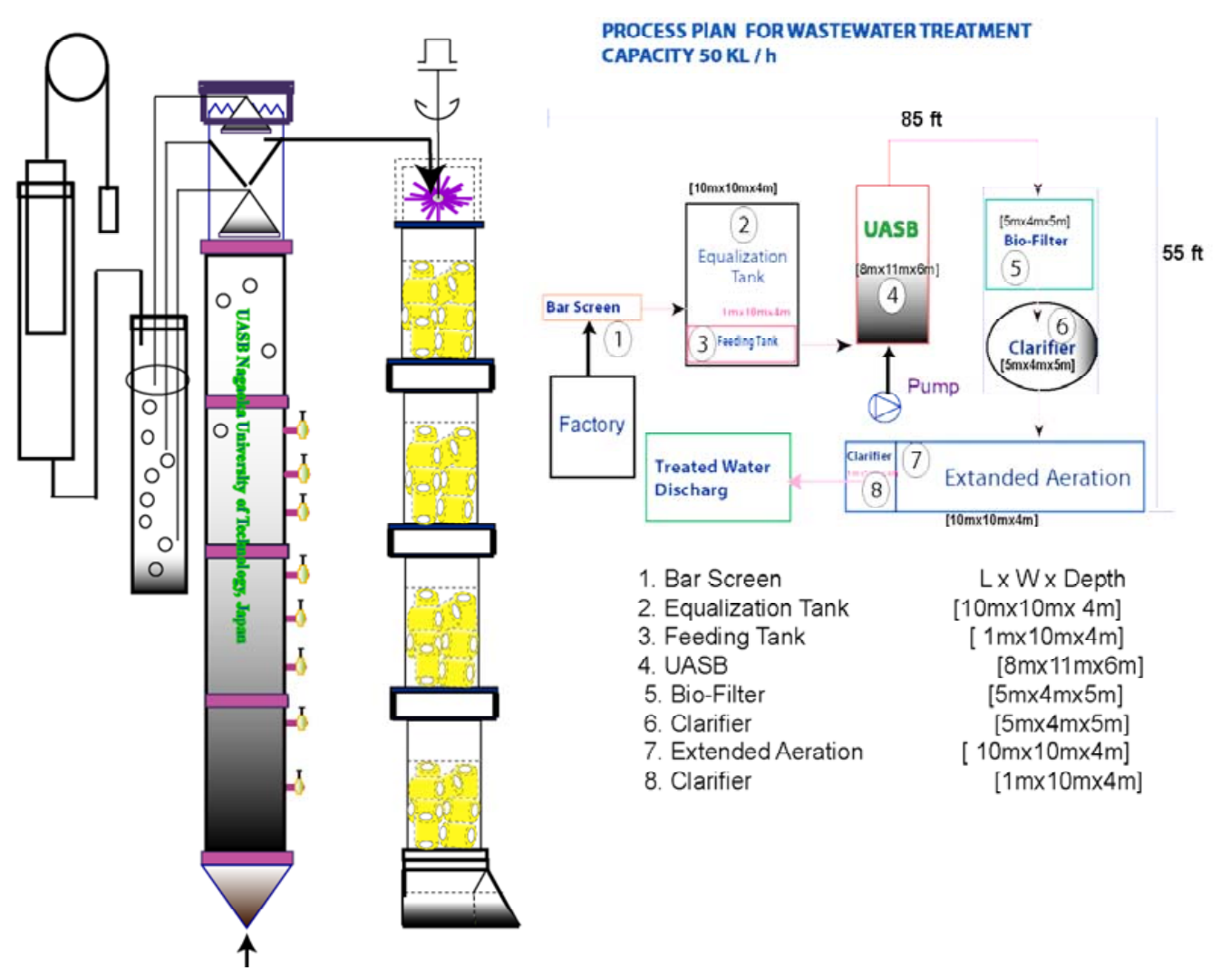

\section{- Fig-1: UASB system for high concentrated $\mathrm{CH} 4$ content Biogas production}

\subsection{Equalization Process}

The raw waste from factory is collected in the equalization tank. It is needed to use a bar screen to protect any solid materials. The equalization tank is designed based on hydraulic retention time (HRT) of around 8-9 hours. Under this process air grids connection is required for mixing the wastewater to protect the solid materials in suspension.

\subsection{Feeding Tank}

Raw wastewater is stored in the feeding tank which is collected from the equalization tank and $\mathrm{pH}$ is maintained at neutral level for auto-biodegradation. The equalized wastewater is then filled into the Feeding Tank. From feeding tank wastewater is fed into the codigester. Feeding is started by using pump under upflow mode of action to the anaerobic reactor.

\subsection{Anaerobic Process}

The anaerobic process followed by Up-flow Anaerobic Sludge Blanket (UASB) process and Bio-filtration was maintained by polyurethane materials followed by down-flow process. The anaerobic process is a high quality treatment process. The anaerobic process is having some favorable opportunities such as; low cost, simple operational mechanism and able to produce less volume of excess sludge and the organic matter can be converted in to energy in the form of biogas. Therefore, anaerobic process is a beneficiary process in terms of environmental protection and the process is economically viable.

The Up-flow Anaerobic Sludge Blanket (UASB) process is a "high rate" anaerobic treatment process. During the earlier development of anaerobic treatment, the main drawback was the low rate of treatment process i.e., the reactor operated under the long Hydraulic Retention Time (HRT). It has already been proved that the UASB system can be widely used in low and high temperature conditions with shorter retention time. The UASB system is a high rate treatment process. Organic loading rate is the most important for determining the shape and size of the reactor. The UASB is successfully used under mesophilic temperature ranged from $25-35^{\circ} \mathrm{C}$. The basic concept of UASB is based on the fact that the flocks of anaerobic bacteria will tend to settle under gravity, when applying a moderate up-flow velocity. The anaerobic bacteria make granule in the size of 3-7 $\mathrm{m}^{2}$. 
Table 1: Textile wastewater treatment by using High Rate Biological process (HRBP)

\begin{tabular}{|c|c|c|c|}
\hline Parameters & $\begin{array}{l}\text { Raw textile } \\
\text { wastewater }\end{array}$ & Treated textile & $\begin{array}{l}\text { DoE Standard in } \\
\text { Bangladesh }\end{array}$ \\
\hline $\mathrm{pH}$ & $9-12$ & 7.5 & $6-9$ \\
\hline Dissolved Oxygen (DO) mg/L & 0.0 & 6.4 & 4.4-8.0 \\
\hline Total Suspended Solids (TSS) mg/L & 1229 & 38 & 150 \\
\hline Total dissolved Solids (TDS) mg/L & 3500 & 1320 & 2100 \\
\hline Biological Oxygen Demand (BOD) mg/L & 550 & 20 & 50 \\
\hline Chemical Oxygen Demand (COD) mg/L & 1448 & 56 & 200 \\
\hline
\end{tabular}

DoE-Directorate of Environment

\subsection{Bio-filtration Process}

The Down-flow Hanging Bio-filtration (DHB) system has been developed first-time in Japan to make the standardized effluent quality of municipal wastewater. The novel combined process of UASB and DHB system is very appropriate technology for the significant reduction of organic matter with pathogenic microorganisms from the UASB effluent. The UASB and DHB combined system has been developed by Professor Heideki Harada and his research group, Nagaoka University of Technology, Nagaoka, Japan. The author was a Post-doctoral student under his guidance and continued higher level of research. The major significant features of DBS system are as follows:

a) Final effluent become standard effluent quality

b) No external aeration is required

c) Final effluent contains more dissolved oxygen

d) Less excess sludge is produced

\section{Results \& Discussions}

\subsection{Characteristics of Textile Wastewater}

The raw textile wastewater is highly polluted with the characteristics of high alkaline in nature, $(\mathrm{pH}=9-12)$, suspended biomass (TSS $=1229 \mathrm{mg} / \mathrm{l}$ ), Chemical Oxygen Demand $(\mathrm{COD}=1448 \mathrm{mg} / \mathrm{l})$, and Biological Oxygen Demand $(\mathrm{BODt}=550 \mathrm{mg} / \mathrm{l})$. Textile Effluent Treatment process is operating under the UASB and Bio-filtration process, which have shown a good treatment process.

\subsection{Increase of Dissolved Oxygen (DO) Level Mechanisms under HRBP}

The dissolved oxygen is very important parameters for aquatic ecosystem which was found zero in the raw wastewater. While in the anaerobic process also found zero level. The dissolved oxygen was increased only for bio-filtration process under the high rate biological process. The mechanisms of DO level increase in the bio-filtration process are shown: The mechanisms of DO level increase in the bio-filtration process are shown:

Reduction of pollution parameters were markedly removed such as; TSS biomass (90\%) through biofiltration process. Dissolved oxygen was increased 5-6 $\mathrm{mg} / \mathrm{l}$ in the final effluent from $0.0 \mathrm{mg} / \mathrm{l} \mathrm{DO}$ level of raw effluent. In addition in the final effluent COD was removed 98\%, BOD 97\% and TSS 98\% removed which shown highly reduction of pollution parameters which also fulfill the standard quality.

Basically our advanced technology is a complete high rate biological process but another type of biological process also operating in Bangladesh which is followed by a lagoon process. The lagoon process is not a cost effective process due to requirement of huge area which is costly. A case study on chemical processes was conducted near Dhaka city. The Chemical ETP process is commonly used in Bangladesh. A detailed comparative cost of chemical and advanced new biological ETP are as follows:

Table 2: The Capital Cost of Chemical ETP (with capacity: 50,000 L/Hour)

\begin{tabular}{l|ll}
\hline & & \\
\hline Design and supervision for construction & $2,00,000.00$ & 1.78 \\
Civil Construction & $80,00,000.00$ & 71.43 \\
Electro-mechanical & $30,00,000.00$ & 26.79 \\
Total capital cost & $112,00,000.00$ & 100 \\
\hline
\end{tabular}

Data source: Direct supervision at the industrial chemical ETP 
Table 3: Total Cost for Chemical ETP (with capacity: 50,000 L/Hour)

\begin{tabular}{l|ll}
\hline & & \\
\hline Capital cost (Depreciation cost) & $2,24,000.00$ & \\
Operational Cost & & 26.70 \\
a). Electricity for Blower and pump operation & $24,00,000.00$ & 66.79 \\
b). Chemical used for treatment & $60,00,000.00$ & 2.67 \\
c). Labor cost & $2,40,000.00$ & 1.34 \\
d). Others & $1,20,000.00$ & 97.50 \\
Sub-total & $87,60,000.00$ & 100.00 \\
Total Cost & $89,84,000.00$ & \\
\hline
\end{tabular}

Table 4: Total cost of New Biological ETP Technology (with capacity: 50,000 L/Hour)

\begin{tabular}{l|ll}
\hline & & \\
\hline Capital cost (Depreciation cost) & 12.56 \\
Operational Cost & $2,24,000.00$ & \\
a). Electricity for Blower and pump & $6,00,000.00$ & 33.63 \\
b). Biological ETP maintenance cost & $6,00,000.00$ & 33.63 \\
c). Labor cost & $2,40,000.00$ & 13.45 \\
d). Others & $1,20,000.00$ & 6.73 \\
Sub-total & $15,60,000.00$ & 87.44 \\
Total Cost & $17,84,000.00$ & 100.00 \\
\hline
\end{tabular}

\section{Total Capital Cost:}

Total amount taka 11.2 million for a period of 50 years as fixed costs required to install the plan. Data were calculated on the basis of straight line method. The annual cost is taka $224,000.00$ only.

\section{Total Cost}

Considering ETP treatment capacity of 50,000 Liter/hour, in Bangladesh, the traditional process on textile wastewater treatment (basically on chemical process) requires total cost taka 89.84 million per year for the chemical ETP process. On the contrary, the new high rate biological ETP requires a total cost taka 17.84 million per year (Table-3 \& 4).

\section{Chemical cost}

The chemical cost for chemical ETP is required taka 60.0 million (66.79\%) and under the HRBT biological ETP the lump sum chemical cost is required 6.0 million (33.63\%) which is $1 / 10^{\text {th }}$ low chemical cost.

\section{Operational Cost}

The total operational cost for Chemical ETP taka is 87.86 million per year while in case of HRBT biological ETP operational cost is taka 15.60 million per year (Table $3 \& 4$ ). The 50,000 Liter /hour flow rate capacity Biological ETP, it is more economical than the chemical ETP process. The operational cost of HRBT ETP is much lower than the chemical ETP process. The advanced biological ETP process is successfully operating without using any chemicals. It is more economical than the chemical alternate process.

\section{Conclusions}

The advanced high rate biological ETP process is hazard free, highly effective, low operational cost, high rate treatment capacity, simple process, low electricity use and also economically viable process than the Chemical ETP process. 


\section{References}

1. C Ciftci and I Oztiirk 1995. Nine years of full-scale anaerobic-aerobic treatment experiences with fermentation industry effluents. Water. Sci. Technol. 32(12): 131-139.

2. G Lettinga and JN Vinken 1980. Feasibility of the up-flow anaerobic sludge blanket (UASB) process for the treatment of low strength wastes. $35^{\text {th }}$ Purdue Industrial waste Conference Proceedings 625-634.

3. JT De Sousa and E Foresti 1996. Domestic sewage treatment in an up-flow anaerobic sludge blanketsequencing batch reactor system. Water Sci. Technol. 33 (3): 73-84.
4. G Lettinga, R Roersma and P Grin 1983. Anaerobic treatment of raw domestic sewage at ambient temperature using a granular bed UASB reactor. Biotech. and Bioengin. 25: 1701-1723.

5. MS. Miah, Chika Tada and Shigeki Sawayama 2004. Enhancement of Biogas production from sewage sludge with the addition of Geobacillus sp. Strain AT1 culture Journal of water Treatment Biology, 40(3): 97-104.

6. MS. Miah, Chika Tada, Yingnan Yang and Shigeki Sawayama (2004). Biogas Production from Sewage Sludge with the Addition of Geobacillus Sp. Strain AT1 Culture. J. of Material Cycle and waste Management, 42(2):20. 